\title{
Numerical Prediction of Creep Rupture Life of Ex-Service and As-Received Grade 91 Steel at $873 \mathrm{~K}$
}

\author{
I.U. Ferdous ${ }^{1}$, N.A. Alang ${ }^{1 *}$, J. Alias ${ }^{2}$, and S. Mohd Nadzir ${ }^{3}$ \\ ${ }^{1}$ Structural Performance and Materials Engineering (SUPREME) Focus Group, Faculty of Mechanical and Automotive Engineering Technology, \\ Universiti Malaysia Pahang, 26600, Pekan, Pahang, Malaysia. \\ Phone: +6094246266 \\ 2Department of Mechanical Engineering, College of Engineering, Universiti Malaysia Pahang, 26300, Gambang, Kuantan, Pahang, Malaysia. \\ ${ }_{3}^{3}$ TNB Research Sdn Bhd, No. 1, Lorong Air Itam, Kawasan Institute Penyelidikan, 43000, Kajang, Selangor.
}

\begin{abstract}
Infallible creep rupture life prediction of high temperature steel needs long hours of robust testing over a domain of stress and temperature. A substantial amount of effort has been made to develop alternative methods to reduce the time and cost of testing. This study presents a finite element analysis coupled with a ductility based damage model to predict creep rupture time under the influence of multiaxial stress state of ex-service and as-received Grade 91 steel at 873 $K$. Three notched bar samples with different acuity ratios of $2.28,3.0$ and 4.56 are modelled in commercial Finite Element (FE) software, ABAQUS v6.14 in order to induce different stress state levels at notch throat area and investigate its effect on rupture time. The strain-based ductility exhaustion damage approach is employed to quantify the damage state. The multiaxial ductility of the material that is required to determine the damage state is estimated using triaxiality-ductility Cock and Ashby relation. Further reduction of the ductility due to the different creep mechanisms over a short and long time is also accounted for in the prediction. To simulate the different material conditions: ex-service and as-received material, different creep coefficients $(A)$ have been assigned in the numerical modelling. In the case of ex-service material, using mean best fit data of minimum creep strain rate gives a good life prediction, while for new material, the lower bound creep coefficient should be employed to yield a comparable result with experimental data. It is also notable that ex-service material deforms faster than as-received material at the same stress level. Moreover, higher acuity provokes damage to concentrate on the small area around the notch, which initiates higher rupture life expectancy. It also found out that, the stress triaxiality and the equivalent creep strain influence the location of damage initiation around the notch area.
\end{abstract}

ARTICLE HISTORY

Received: $25^{\text {th }}$ May 2021

Revised: $21^{\text {st }}$ Aug 2021

Accepted: $1^{\text {st }}$ Sept 2021

\section{KEYWORDS}

Creep;

Damage;

Ductility;

Grade 91 steel;

Notch

\section{INTRODUCTION}

In the modern era, power producers struggle to increase power plant efficiency and obtain the required power output at optimum cost. It is essential that the system components must not fail while in service to ensure plant safety and to avoid an expensive unplanned shutdown. Due to relatively low cost and ability to sustain in the high-temperature environment, Grade 91 steel has become important and widely used in the power plant industry. After a long time in service, however, creep damage in terms of voids and cracks have been inspected [1] in the components. The damage concentrates at the location with a higher constraint which attributed by the irregularity or sudden change in shape, notches, elbows, fillets as well as the weldment. In the laboratory, the influence of constraint or multiaxial stress state on creep rupture life has been investigated using the notched bar specimen $[2,3]$. The notches are initiated on the uniaxial creep sample to induce non-uniform stress-strain distribution, thus a complex stress state. The experiment parameter is usually designed so that the material experiencing a real service condition; however, it is a long-term testing that is impractical due to the cost and time-consuming. For this reason, Finite Element (FE) modelling has been performed by many researchers [3-5] to reduce the total testing duration.

Experimental and numerical modelling works have been performed on the notched bar specimens with various acuity levels to investigate the effect of multiaxial stress state on the creep rupture behaviour. Goyal and Laha [6] carried out a creep test on a smooth and notched bar of $9 \mathrm{Cr}-1$ Mo steel with notch acuity in the range of $1-20$ and found that the presence of notch leads to notch strengthening behaviour. This behaviour, however, tends to saturate to a sharp notch. In another study on P91 steel, Zhao et al. [7] reported that the damage initiation position is influenced by the notch radius and external stress. For sharp notch, the damage or crack propagated both towards the notch root and the centre of specimens. A new crack that began from the specimen centre was also observed before a fully fractured was predicted. Similar observation on notch strengthening behaviour was also reported for this material. Note that creep deformation, damage initiation and growth processes are controlled by the stress components such as hydrostatic stress, principal stress and von Mises stress. 
Creep deformation and damage mechanism is a complex process and is currently not fully understood. The mechanism involves dislocation slip and climb, diffusional flow, and interaction between them. Due to the difficulty to mathematically model such processes, mechanistic modelling has been performed where the phenomenon behaviour is quantified by the change in mechanical property observed during physical testing in the laboratory. For instance, the damage at the microscopic level can be related to the change in ductility of the material. At a shorter time, creep ductility appears to be high and constant. As time increases, ductility appears to be influenced by the strain rate and remains constant again for a very long time. The fractography examination on the crept specimen found that at high stress creep is dominated by dislocation; therefore, the transgranular fracture with significant plastic deformation and ductile dimples are clearly seen [8]. At low stress or a longer time, the diffusional creep process takes place, and the intergranular fracture with limited deformation is observed [9]. Zhang et al. [10] studied the effect of two stress regimes due to different creep mechanisms (at high and low-stress levels) on creep crack growth rate on Cr-Mo-V steel. Finite element analysis coupled with a ductility exhaustion-based damage model was implemented. Considering the two-creep mechanism when simulating the crack growth rate gives a better prediction. In another study, Tu et al. [11] investigated the effect of different creep mechanisms on creep behaviour and strain rate using a small specimen technique and found that the error may occur at the transition between creep mechanisms. Therefore, more attention should be given when simulating this area.

The ductility exhaustion based damage model has been widely employed to quantify the damage state of the material under creep deformation. The model assumed that failure occurs when the creep strain of material reaches the critical strain or ductility. Creep ductility is an important parameter in this damage model and its input value determines the accuracy of the prediction. Uniaxial creep ductility can be measured in the laboratory by performing the creep rupture test. The laboratory measured creep ductility value, however, is found to be substantially scattered that may be attributed to tensile instability of necking during tertiary creep [12]. For that reason, the best fit line is usually plotted to represent the mean value of creep ductility. Under multiaxial stress state, however, the standard method to determine the creep ductility is not well developed. An effort has been made to quantify the relation between creep strain and triaxiality factors, and the most widely discussed in literature includes Cock and Ashby [13], Rice and Tracey [14] and spindler [15] models. Cock and Ashby model assumed that ductility ratio (multiaxial/uniaxial) and triaxiality factor parameters could be related by the hyperbolic sines function where the other two models assumed exponential relation. All models agreed that the creep strain is inversely proportional to the triaxiality factor. However, the discrepancy between the models are significant as the triaxiality level increases.

Due to the changes in the microstructure of the ex-service material as exposed to high temperature and stress for a long period, the material shows lower creep strength. Li et al. [16] conducted a study of microstructural characterisation on the virgin and service exposed P91 steel and found out that there was a drastic difference in microstructure between virgin and service exposed steel. In a similar study, it is also found out that this steel softened from an initial hardness of $225 \mathrm{HV}$ to only $145 \mathrm{HV}$ after service exposure. This implies that the ex-service material may deform at a higher strain rate than as-received (new) material conditions at the same stress level. This paper intends to numerically evaluate the creep rupture time of Grade 91 steel with different material conditions of ex-service and as-received. The influence of the multiaxial stress state is investigated by simulating the creep sample with various notch geometries.

\section{EXPERIMENTAL SETUP}

\section{Material and Specimen}

A total of 4 creep samples with two acuity levels (of 2.28 and 4.56) were extracted from Grade 91 steel pipe in the longitudinal direction. Note that the acuity ratio is defined as the ratio of the narrowest cross section's diameter to the notch radius. Figure 1 shows the detailed dimension of the creep specimen used for in-house creep testing. The microstructure of the material (Grade 91 steel) is shown in Figure 2. This image was taken prior to creep testing. The material shows clear tempered martensite with prior austenite grain boundary (PAGB). Additional creep rupture life data of notched bar with an acuity of 3.0 were collected from literature [17] and used to validate the FE modelling. Note that the data from literature was obtained from the ex-service pipe; therefore a degree of degradation in terms of creep strength due to ageing is anticipated.

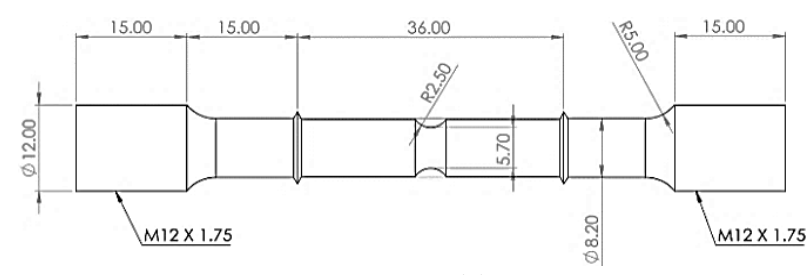

(a)

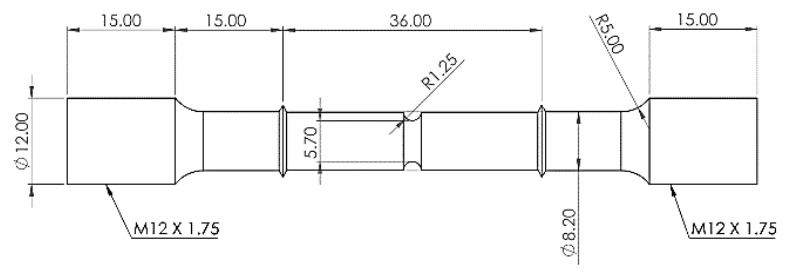

(b)

Figure 1. Detailed dimension of creep specimen: (a) acuity $=2.28$ and (b) acuity $=4.56$. 

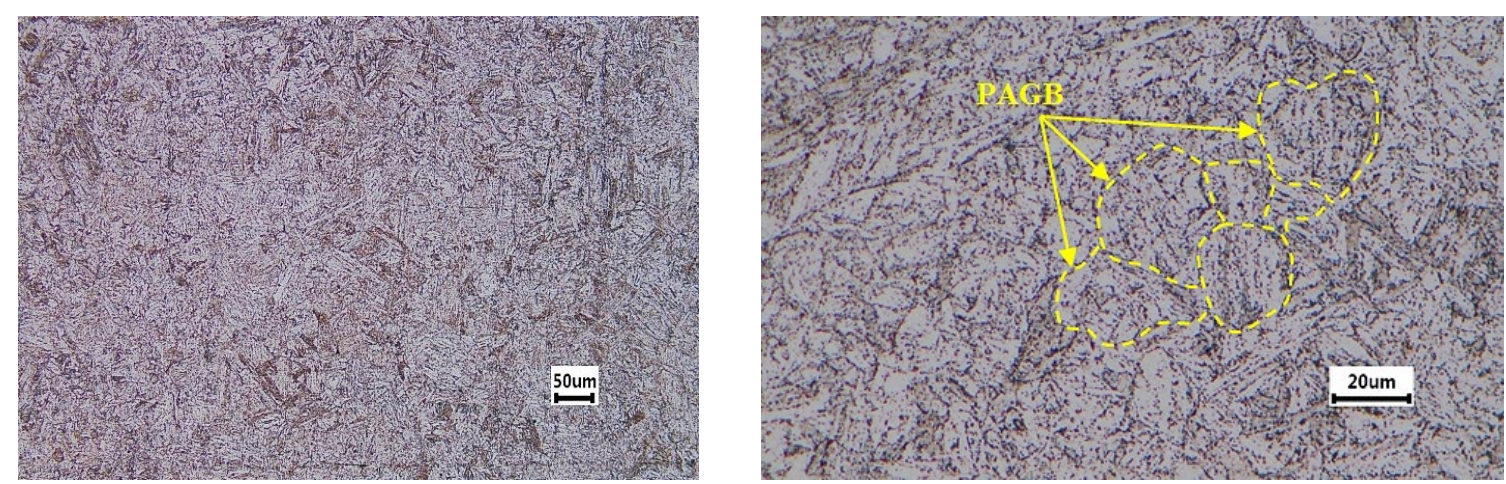

Figure 2. Optical micrograph of (a) tempered martensite (low magnification image), and (b) tempered martensite with PAGB (high magnification image).

\section{Creep Rupture Test}

The creep rupture test was performed according to the test procedure ASTM E292 [18]. The test is carried out using a dead load creep machine equipped with a furnace to provide a high temperature environment surrounding the specimen. Figure 3(a) shows the available creep machine in Universiti Malaysia Pahang (UMP) and its main components. The machine has a lever load ratio of 1:50. The specimen was held inside the furnace. Axial displacement was measured using a linear variable differential transducer (LVDT) that was installed using a clamp holder. Three K-type thermocouples were attached to the specimen at three different points (upper, middle and lower) to measure the temperature before and during the testing. The specimen was heated to a specified temperature, which in this present study is $600^{\circ} \mathrm{C}$. After reaching the desired temperature, the specimen was left inside the furnace for at least 8 hours to ensure the temperature is uniform for the entire specimen. The pre-determined load was then applied to the specimen through the lever. Both temperature and displacement were continuously measured and monitored so that the maximum deviation between all thermocouples during the test did not exceed $2{ }^{\circ} \mathrm{C}$. Note that the creep displacement data was taken every 2 minutes during the primary stage and increased to every 10 minutes during secondary deformation. Figure 3(b) and Table 1 show the experimental setup and the test matrix for the creep test, respectively.

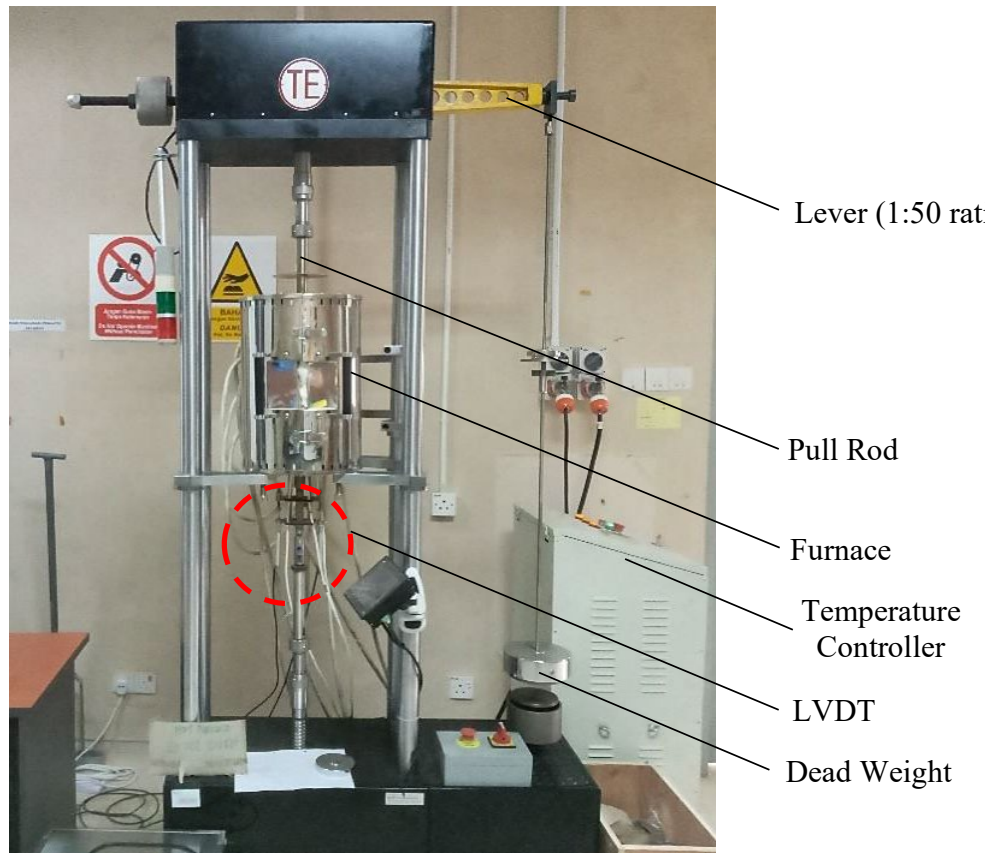

(a)

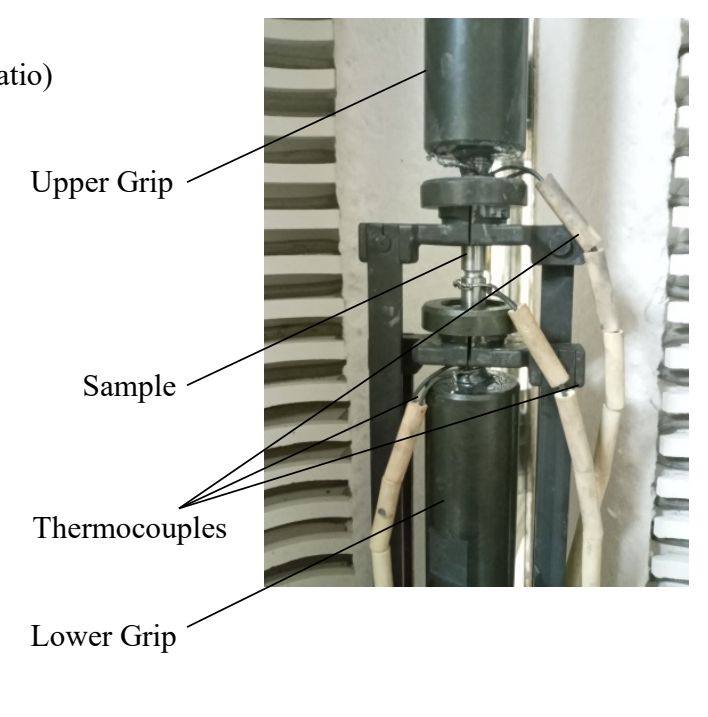

(b)

Figure 3. Experimental setup: (a) overall and (b) close-up on creep specimen. 
Table 1. Test matrix for creep-rupture testing.

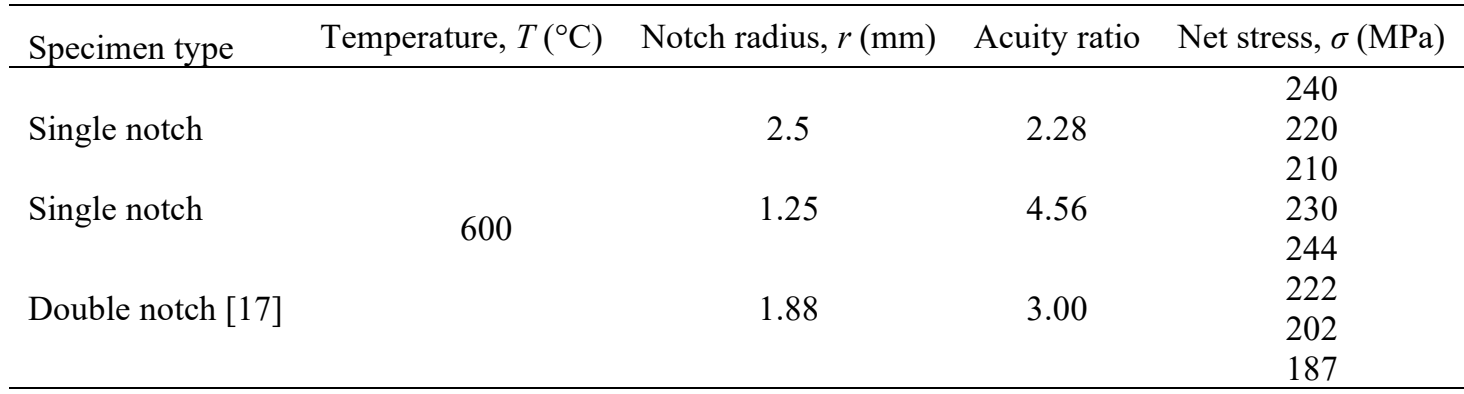

\section{FINITE ELEMENT MODELLING}

ABAQUS v6.14 FE software was used for numerical modelling. The notched bar sample was modelled with a twodimensional (2-D) axis-symmetric model. Taking into the advantage of the symmetry of the sample, only one-quarter of the overall specimen geometry was modelled. The model was structured meshed in two major sections; notch area and uniform section. During meshing quadrilateral element with a reduced integration scheme (CAX4R) was applied. The Abaqus 'partition' option has been applied to aid the smaller meshing generation around the notch area. An illustration of the sliced face is shown in Figure 4(b). The three different FE models consisted of 1360-4080 elements and 14794245 nodes. The FE mesh was developed adequately small, particularly around the notch root area, to correctly represent the overall stress distribution and prevent the convergence problem during FE analysis. An appropriate boundary condition is applied, including the load along the top surface, and the nodes along the bottom surface are restrained in the y-direction, as shown in Figure 4(c).

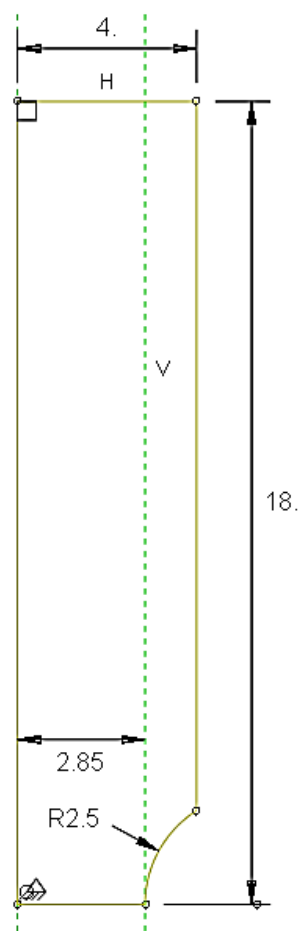

(a)

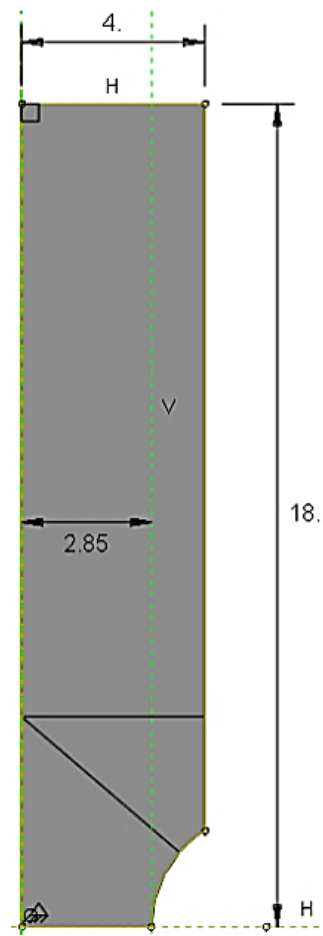

(b)

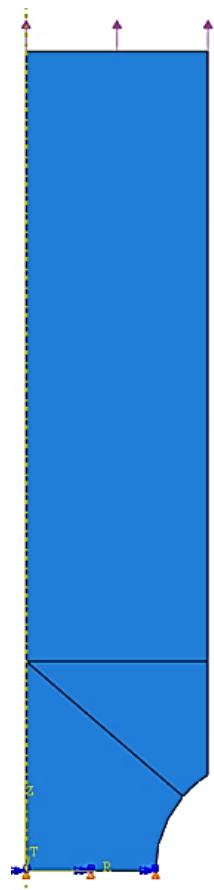

(c)

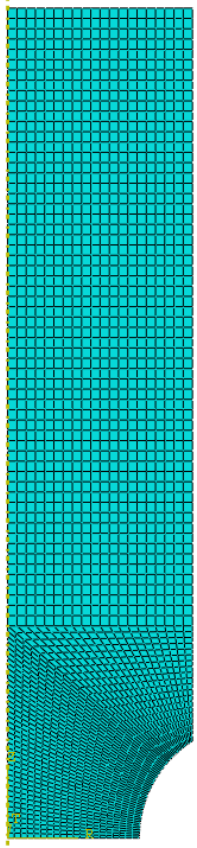

(d)

Figure 4: FE model of notched bar: (a) sketching, (b) partition, (c) constraint and load and (d) FE mesh.

Constraint-based multiaxial ductility models are an important area of modelling development. The fact that creep is stress state-dependent, it is important to base the creep damage models which address this issue. There are several models such as Cocks and Ashby [12], expressed in Eq. (1a) and Rice and Tracey [14], given in Eq. (1b), which is capable of predicting intergranular fracture during power law creep. When the $\varepsilon_{f}^{*}$ is defined as the creep ductility under a multiaxial stress condition and $\varepsilon_{f}$ defined as the uniaxial creep ductility, an approximation of the ratio of these two parameters in terms of triaxial stress and Norton's law creep component, $n$ can be expressed as follows:

$$
\frac{\varepsilon_{f}^{*}}{\varepsilon_{f}}=\sinh \left[\frac{2}{3}\left(\frac{n-0.5}{n+0.5}\right)\right] / \sinh \left[2\left(\frac{n-0.5}{n+0.5}\right) \frac{\sigma_{m}}{\sigma_{e}}\right]
$$




$$
\frac{\varepsilon_{f}^{*}}{\varepsilon_{f}}=1.65 \times \exp \left(-1.5 \frac{\sigma_{e}}{\sigma_{m}}\right)
$$

Here, equivalent stress and mean stress can be expressed by Eq. (2) and Eq. (3), respectively.

$$
\begin{gathered}
\sigma_{e}=\frac{1}{\sqrt{2}}\left[\left(\sigma_{1}-\sigma_{2}\right)^{2}+\left(\sigma_{2}-\sigma_{3}\right)^{2}+\left(\sigma_{3}-\sigma_{1}\right)^{2}\right]^{1 / 2} \\
\sigma_{m}=\frac{\sigma_{1}+\sigma_{2}+\sigma_{3}}{3}
\end{gathered}
$$

Notice that the relationship between the two parameters; reduction of ductility and triaxiality ratio, $h\left(\sigma_{m} / \sigma_{e}\right)$ suggested by the two models are consistent at the uniaxial plane stress condition but do not agree well when the level of constraint increases. Recently, Alang et al. [19] proposed a simple approximation that suggests a linear relation between multiaxialto-uniaxial ductility and triaxiality ratio (normalised to a plane stress condition, $\mathrm{h}=0.33$ ).

It was observed that the uniaxial failure strain, both MG failure strain and strain at failure depending upon strain rate and stress. The failure strain drops over the creep time, which indicates that the controlled failure mechanisms are different at short and long-term creep. To fit the failure strain data from high to low-stress regimes, a single function describing failure strain as a function of creep strain rate is employed and mathematically can be written as:

$$
\varepsilon_{f}=f\left(\dot{\varepsilon}_{c}\right)=\frac{\varepsilon_{f_{\max }}+\varepsilon_{f_{\min }}\left(\frac{\dot{\varepsilon}_{c}}{\dot{\varepsilon}}\right)^{-\alpha}}{\left(\frac{\dot{\varepsilon}_{c}}{\dot{\varepsilon}}\right)^{-\alpha}+1}
$$

A total of 69 creep data from various material conditions and heat [20] were analysed to derive the creep constant ( $A$ and $n$ ) and $\alpha$. It is clearly shown that the creep deformation obeys the Norton power-law relation as given in Eq. (5). The data can be grouped into two slopes, separated at stress, $\sigma^{*}=125 \mathrm{MPa}$, which is equivalent to half of the material yield strength $\left(0.5 \mathrm{~S}_{\mathrm{y}}=125 \mathrm{MPa}\right)$. The mean data curve, as well as the upper/lower bounds curve, were plotted for minimum creep strain rate against stress data, and the corresponding $A$ and $n$ were determined. These values were employed in the modelling to predict the rupture life of the notched bar. Moreover, the prediction was made by changing the value of $A$ and keeping the value of $n$ constant. Note that the upper and lower bound curves shown in Figure 5 were constructed so that $99 \%$ of the data points were bounded between the curves. Tables 2 and 3 tabulate the static and creep properties of Grade 91 steel at $873 \mathrm{~K}$. In addition, the best fit line of the MG failure strain is drawn (as shown in Figure 6) according to Eq. (4) and is adopted in the ABAQUS using user-defined field subroutine USDFLD.

$$
\dot{\varepsilon}_{m}=A \sigma^{n}
$$

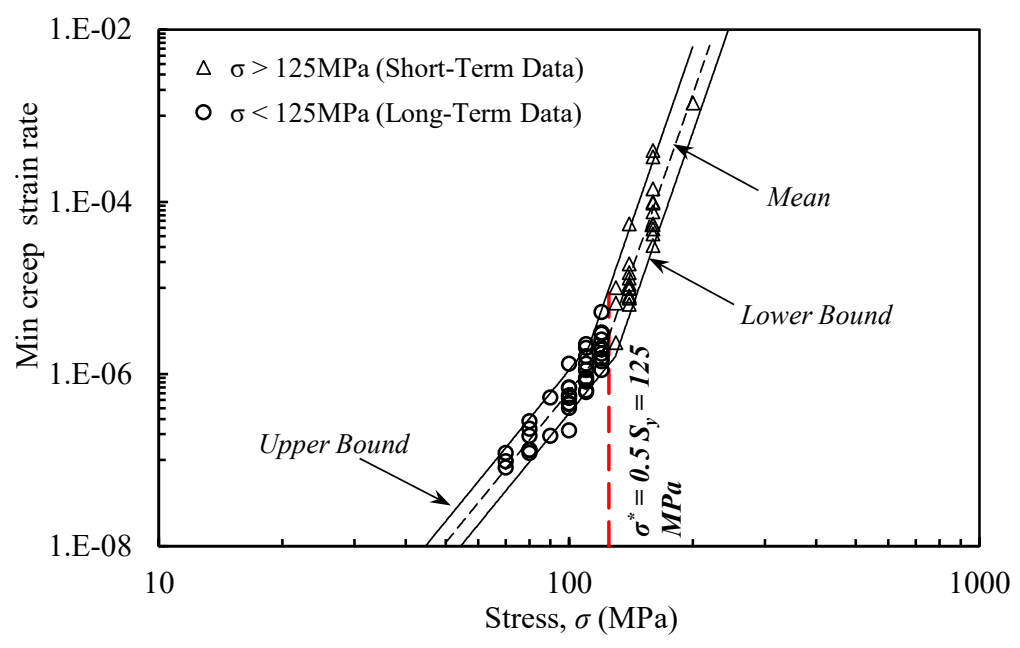

Figure 5. Minimum creep strain rate against stress of Grade 91. 


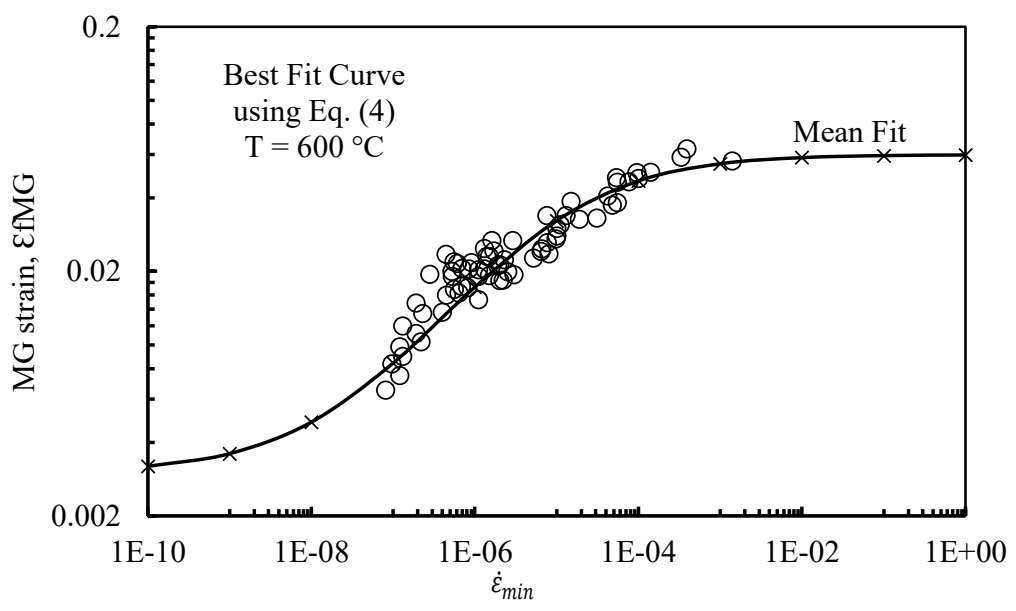

Figure 6. Ductility against creep strain rate of Grade 91 steel.

It was found that considering two stress-regimes (short- and long-term time) in FE simulation gives better accuracy compared when employing a single value of $A$ and $n$ [8]. Choudhary [21] explored the creep behaviour of 9Cr-1Mo ferritic steel, and the study exhibited that the steel obeyed power law in the stress dependence of rupture life and exhibited distinct low and high-stress regimes characterised by separate values of the power-law exponent. To simulate different material conditions of ex-service and as-received, the creep coefficient based on mean and upper/lower bounds curve is simulated. The creep exponent, $n$, however, is kept constant, assuming the number of analysed data is sufficient to preserve the slope of minimum creep strain data. It is anticipated that incorporating the lower/upper bounds value of $A$ will provide the highest and lowest possible creep life of the material. A stronger material should have a lower $A$ value which shows higher resistance to the creep deformation compared to weaker material.

Table 2. Statics mechanical properties [22] of Grade 91 steel at $873 \mathrm{~K}$.

\begin{tabular}{lcc}
\hline$E(\mathrm{GPa})$ & $K(\mathrm{MPa})$ & $N$ \\
\hline 164 & 673.9 & 0.16 \\
\hline
\end{tabular}

Table 3. Creep properties (see Figure 5) of Grade 91 steel at $873 \mathrm{~K}$.

\begin{tabular}{|c|c|c|c|c|}
\hline \multirow{2}{*}{ Best fit curve } & \multirow{2}{*}{$A_{S}\left(\mathrm{MPa}^{-\mathrm{n}} / \mathrm{h}\right)$} & \multirow{2}{*}{$A_{L}\left(\mathrm{MPa}^{-\mathrm{n}} / \mathrm{h}\right)$} & \multicolumn{2}{|c|}{ Stress exponent, $n$} \\
\hline & & & High stress, $\boldsymbol{n}_{\boldsymbol{s}}$ & Low stress, $\boldsymbol{n}_{\boldsymbol{L}}$ \\
\hline Mean & $3.77 \times 10^{-35}$ & $1.32 \times 10^{-18}$ & & \\
\hline Lower Bound & $1.37 \times 10^{-35}$ & $7.32 \times 10^{-19}$ & 13.76 & 5.84 \\
\hline Uper Bound & $1.37 \times 10^{-34}$ & $2.32 \times 10^{-18}$ & & \\
\hline
\end{tabular}

In the present study, the ductility exhaustion based damage model has been employed to predict the creep life. The failure is assumed to occur when the accumulated creep strain reaches the critical strain. Mathematically, the model can be expressed as:

$$
\omega=\int_{0}^{t} \dot{\omega} d t=\int_{0}^{t} \frac{\dot{\varepsilon}_{c}}{\varepsilon_{f}^{*}} d t
$$

The $\varepsilon_{f}^{*}$ and $\dot{\varepsilon}_{c}$ in Eq. (6) are the multiaxial ductility and creep strain rates, respectively. When the $\omega$ of an element reaches the value of 0.99 , the elements are considered to be fully damaged, and local failure is predicted. In this simulation, the elastic modulus is reduced by $99 \%$ from the original value when the damage reaches $\omega=0.99$. The progressive damage simulation as discussed above is implemented in the ABAQUS user-defined field subroutine USDFLD. The summary of damage calculation is presented as a flow chart in Figure 7. 


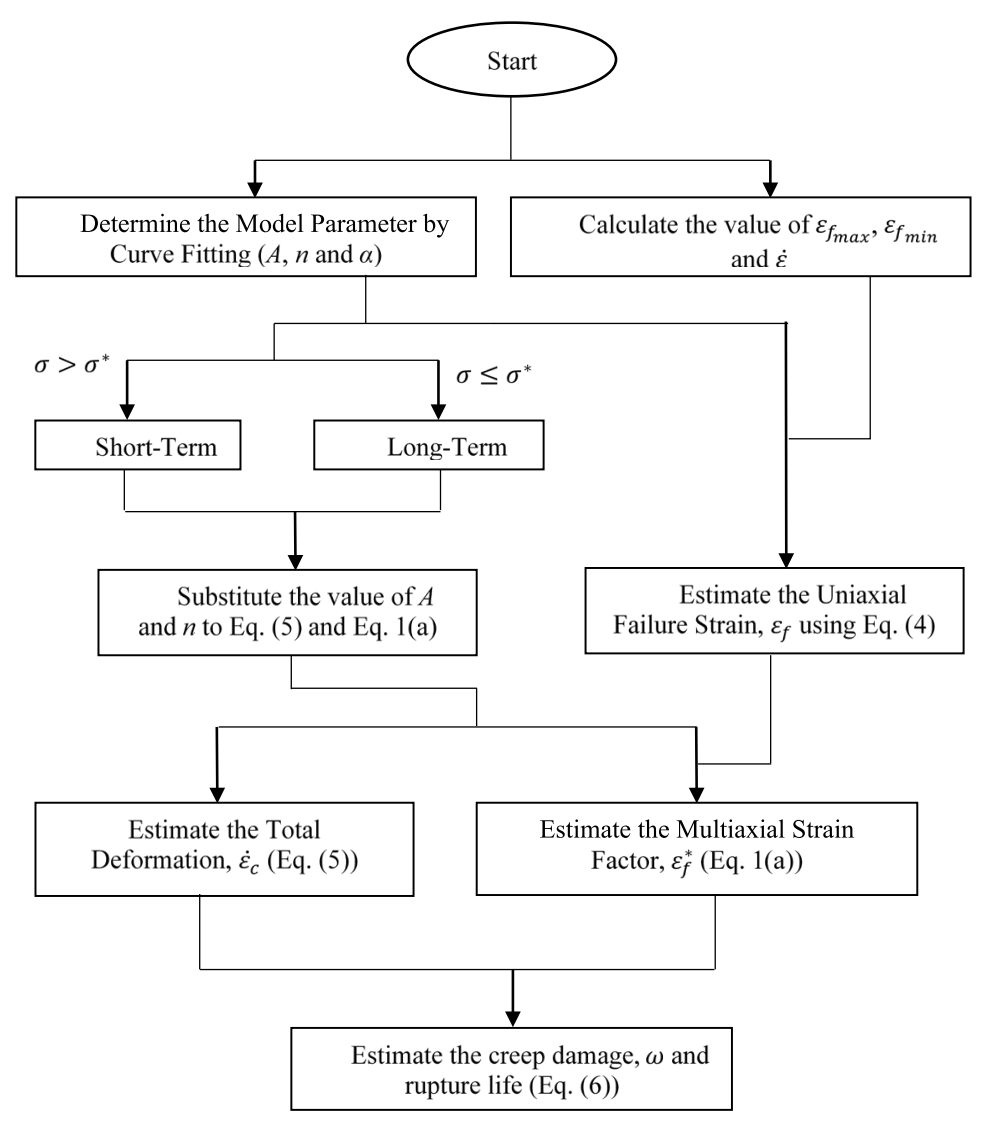

Figure 7. Flow chart of creep damage calculation.

\section{RESULTS AND DISCUSSION}

A total of eight notched specimens were modelled in the FE software having an acuity ratio of 2.28, 3.0, and 4.56; and the rupture life is determined using the ductility exhaustion based damage model (Table 4). The applied stresses were the same as the experimental data. During FE analysis, different values of creep coefficient $(A)$, considering the mean, upper and lower bounds of minimum creep strain rate data is employed to differentiate the material states. The rupture life was also determined using the mean, upper, and lower bound value of creep coefficient $(A)$ for all acuities and stress levels. Comparing between the different notch acuity, there is evidence of notch strengthening effect where the creep rupture life increases as the acuity ratio increases. In Figure 8, experimental rupture data is plotted along with the mean, lower/upper bound prediction curve. It can be observed that all experimental data fall within the upper and lower bound prediction curves. To be precise, in the case of as-received material, the experimental data goes with the upper bound prediction line for both acuity ratios, which is obtained by employing the lower bound creep coefficient. The value of $A$ can be further optimised to yield an accurate prediction. It implies that, at the same stress level, the ex-service material deformed at a higher rate, thus lower rupture life compared to as-received material.

The result indicates that the as-received material manifests a longer creep life than the ex-service material under the same loading condition. On the other hand, the experimental rupture life of ex-service material fits along with the mean best fit data curve, with an exception for the stress level $202 \mathrm{MPa}$ for ex-service material, where mean prediction slightly underestimates the rupture life. However, it is evident that the applied method is capable of predicting the rupture life. Sklenicka et al. [23] conducted a study to determine the creep behaviour of the $9 \% \mathrm{Cr}$ steel in as-received condition and after long-term ageing and found out that the creep rupture life of the aged material is considerably shorter than the asreceived material. He concluded that the shorter rupture life of the aged material might be due to the dominance of microstructural degradation for the reason of coarsening and/or perishing secondary phase precipitates and reorder of dislocation structure as the material experiences long-term creep exposures. In addition, an almost similar slope of minimum creep strain rate data was observed for both material conditions which may be due to the same creep deformation and fracture mechanisms. In another study, Melody van Rooyen et al. [24] reported that higher strain rates are observed for the $12 \% \mathrm{Cr}$ ex-service material compared to virgin or as-received material. The highly damaged material shows a tertiary-dominated creep deformation which leads to early rupture. In addition, service-exposed material has a lower hardness reading which indicates some degree of degradation in its properties. 
Table 4. Notched bar test result.

\begin{tabular}{|c|c|c|c|c|c|}
\hline \multirow{2}{*}{ Acuity ratio } & \multirow{2}{*}{ Net stress, $\sigma(\mathrm{MPa})$} & \multirow{2}{*}{$\begin{array}{c}\text { Experimental rupture life, } t_{f} \\
\text { (hours) }\end{array}$} & \multicolumn{3}{|c|}{ FE Prediction rupture life, $t_{f}$ (hours) } \\
\hline & & & Average & Upper bound & Lower bound \\
\hline \multirow[t]{3}{*}{2.28} & 240 & 52 & 40 & 99 & 11 \\
\hline & 220 & 245 & 117 & 287 & 38 \\
\hline & 210 & 398 & 212 & 517 & 68 \\
\hline 4.56 & 230 & 200 & 117 & 260 & 60 \\
\hline \multirow[t]{4}{*}{$3.00[17]$} & 244 & 49 & 43 & 111 & 14 \\
\hline & 222 & 139 & 145 & 351 & 57 \\
\hline & 202 & 778 & 442 & 1008 & 169 \\
\hline & 187 & 942 & 1012 & 2075 & 388 \\
\hline
\end{tabular}

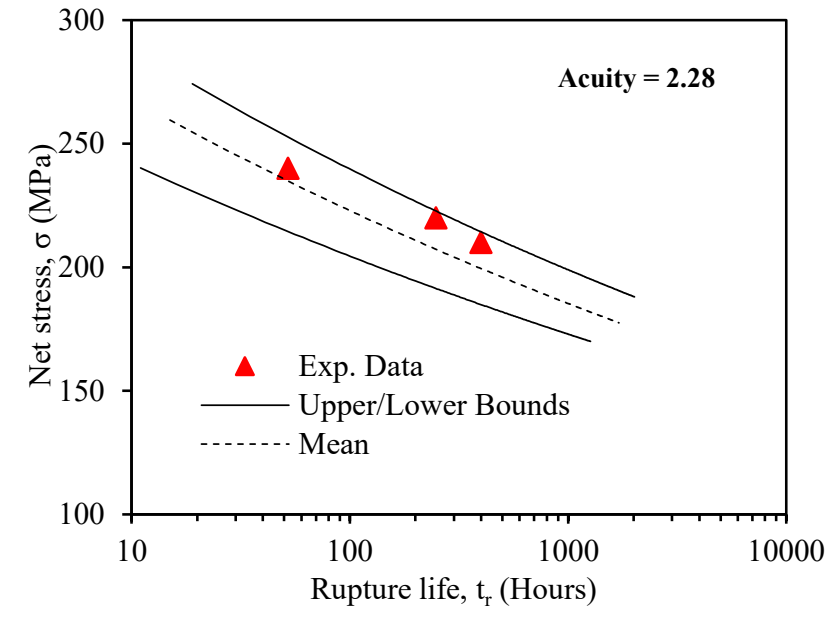

(a)

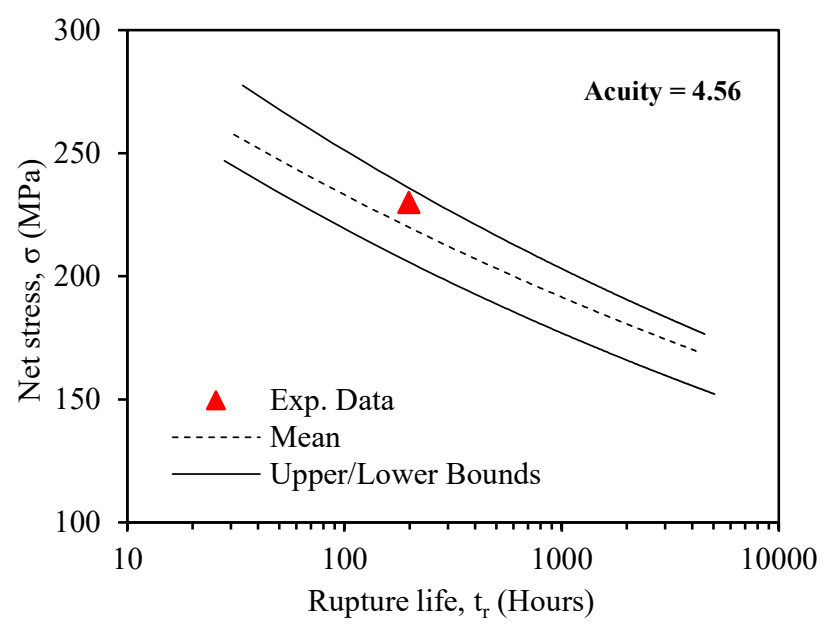

(b)

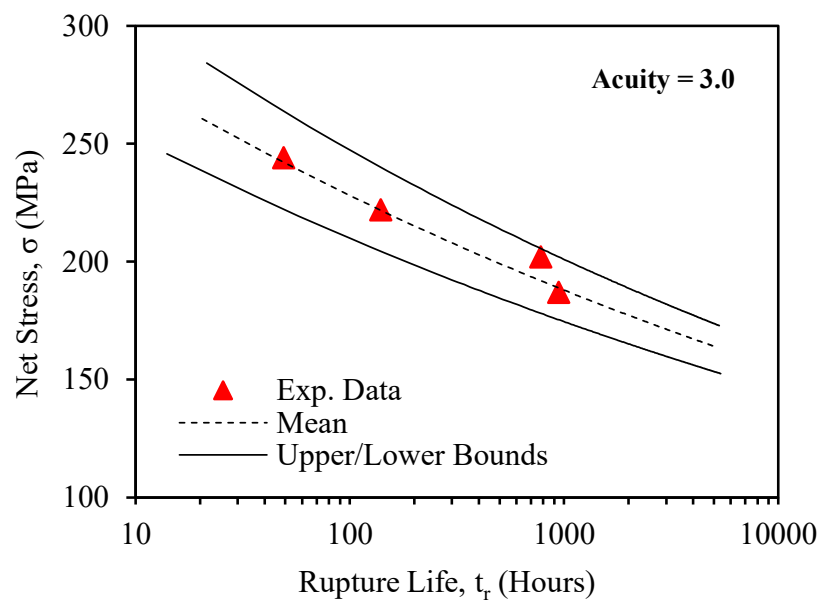

(c)

Figure 8. Rupture life of notched bar: (a) acuity $=2.28$, (b) acuity $=4.56$, (c) acuity $=3.0$.

Figure 9 to Figure 11 show the distribution of creep damage at a notch region for the acuities of 2.28, 4.56, and 3.0, respectively, at different creep times under the influence of different stress levels. It can be observed from the figures that the damage distribution at the notch area for the same notch constraint is similar regardless of different applied stresses. The damage accumulation at each element across the notch area also appears to be increasing over time. At the initial time $\left(\mathrm{t}=0.1 \mathrm{t}_{\mathrm{r}}\right)$, for acuity 2.28 , near the notch root, the maximum creep damage occurs, and as time progresses, the maximum damage is aimed toward the centre of the notch. This phenomenon is indifferent to all applied loads. In the case of acuity 3.0, as seen in Figure 11, the maximum damage emerges first near the notch root and then moves toward the notch subsurface as it stabilises. In contrast, the maximum damage is sustained near the notch root for acuity 4.56 . It implies that the location of the damage does not affect by time. In another observation, referring to Figure 12(a) to 12(c), for acuity 2.28, the damage expands over a large region around the notch. As the value of acuity increases, the damage gets confined around the notch region. This dependency of damage on the acuity causes the variation of the lifetime of the material. The large value of acuity shows a longer lifetime over the smaller value of acuity. It has been reported that for a sharp notch, low-stress level and relatively higher temperature, the damage is localised, thus, leads to crack propagation [25]. In the present study, however, the time taken for a few elements to fully damage $(\omega=0.99)$ has no significant difference from the time taken for the damage to develop in the entire notch ligament. This indicated that no 
stable damage or crack growth occurred before the sample was broken. The study sample is relatively blunted, which is perhaps an insufficient constraint to cause stable crack propagation to happen.
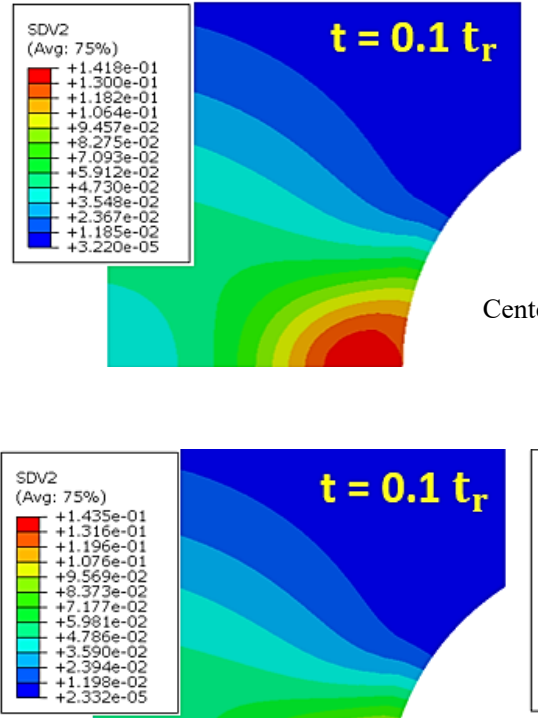

2

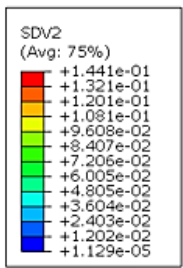

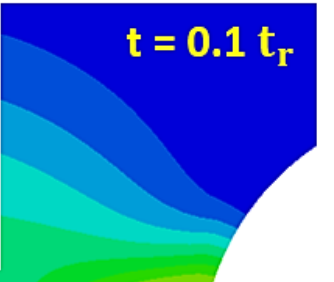

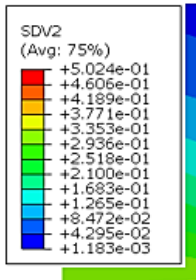

Center

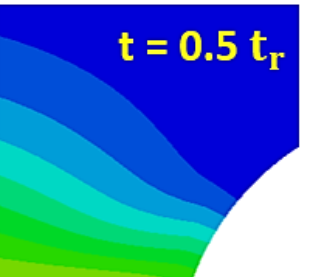

Notch Root

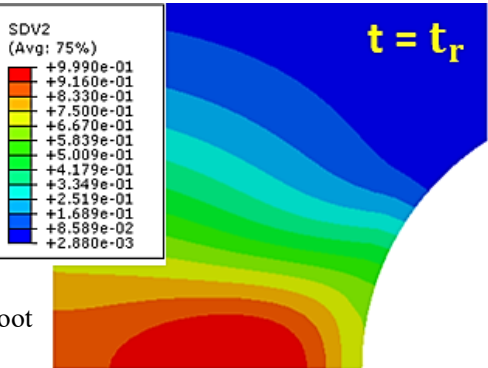

(a)
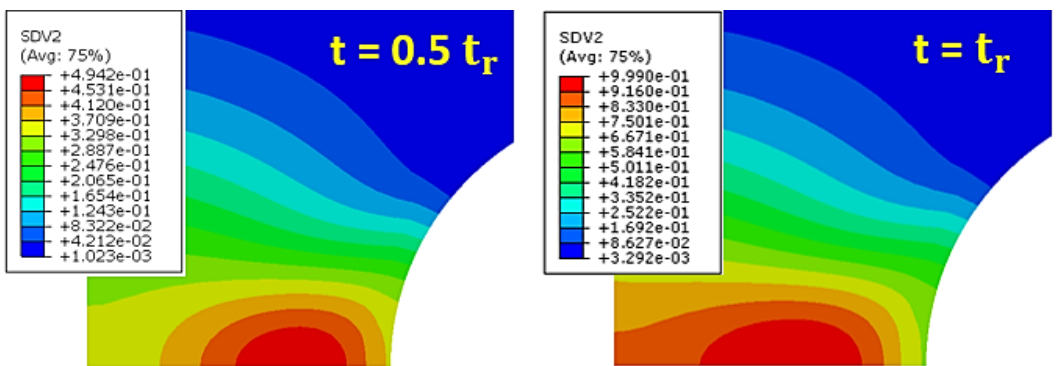

(b)
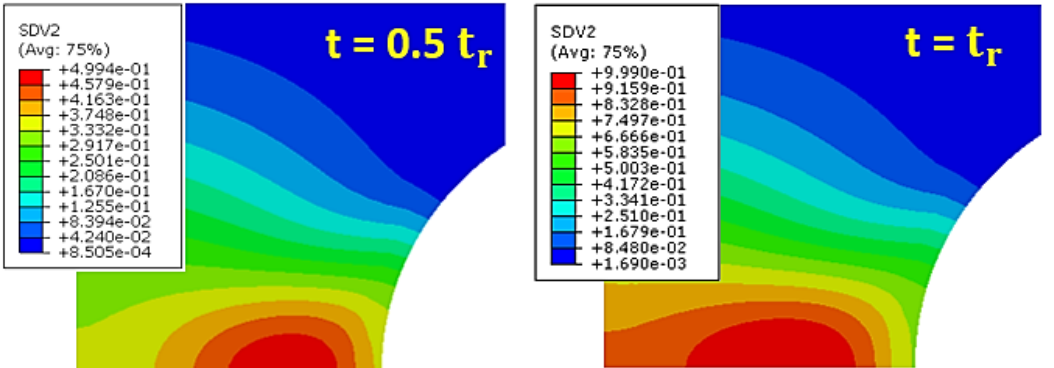

(c)

Figure 9. Creep damage distribution around the notch region at different creep time for acuity $=2.28$ at (a) net stress $=$ $210 \mathrm{MPa}$, (b) net stress $=220 \mathrm{MPa}$ and (c) net stress $=240 \mathrm{MPa}$.
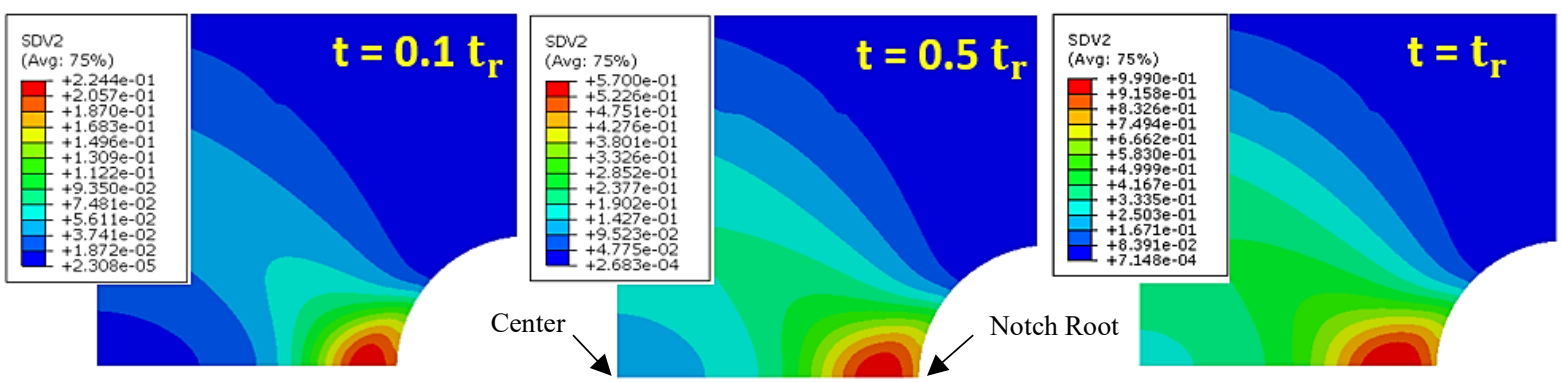

Figure 10. Creep damage distribution around the notch region at different creep time for acuity $=4.56$ and net stress $=$ $230 \mathrm{MPa}$. 

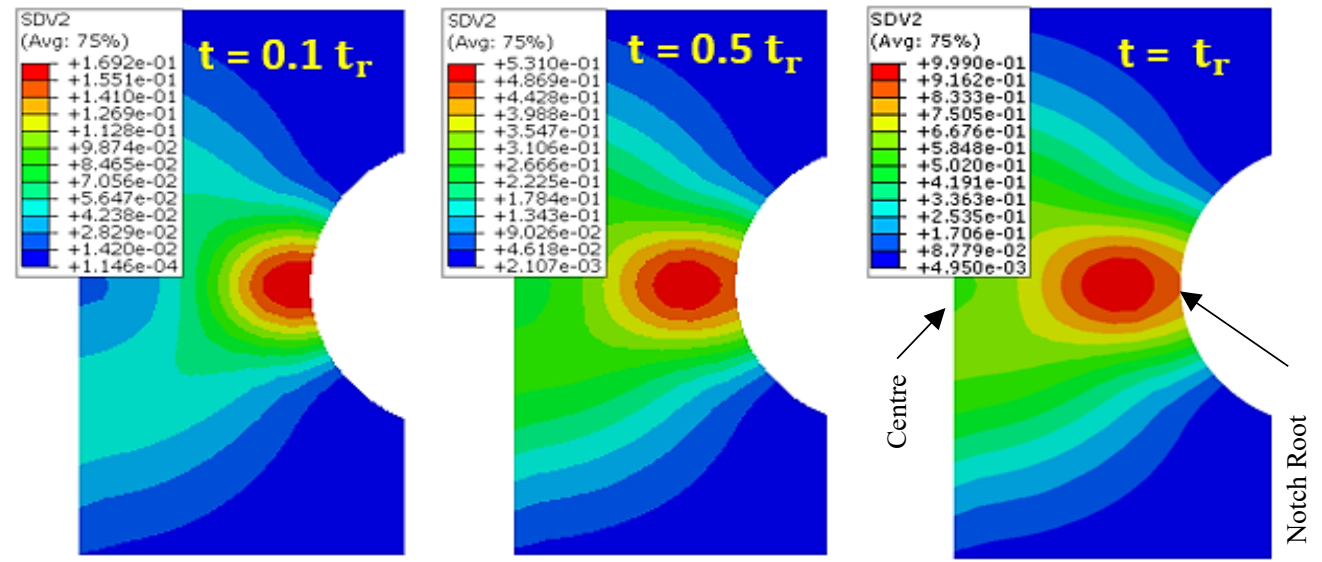

(a)
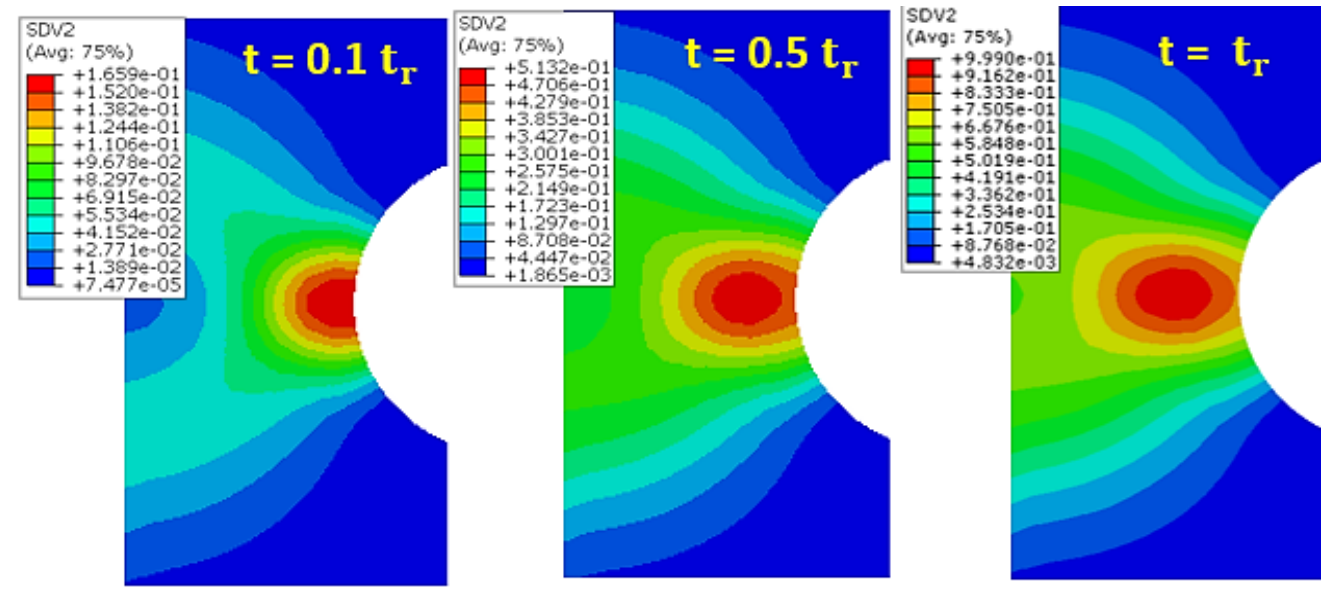

(b)
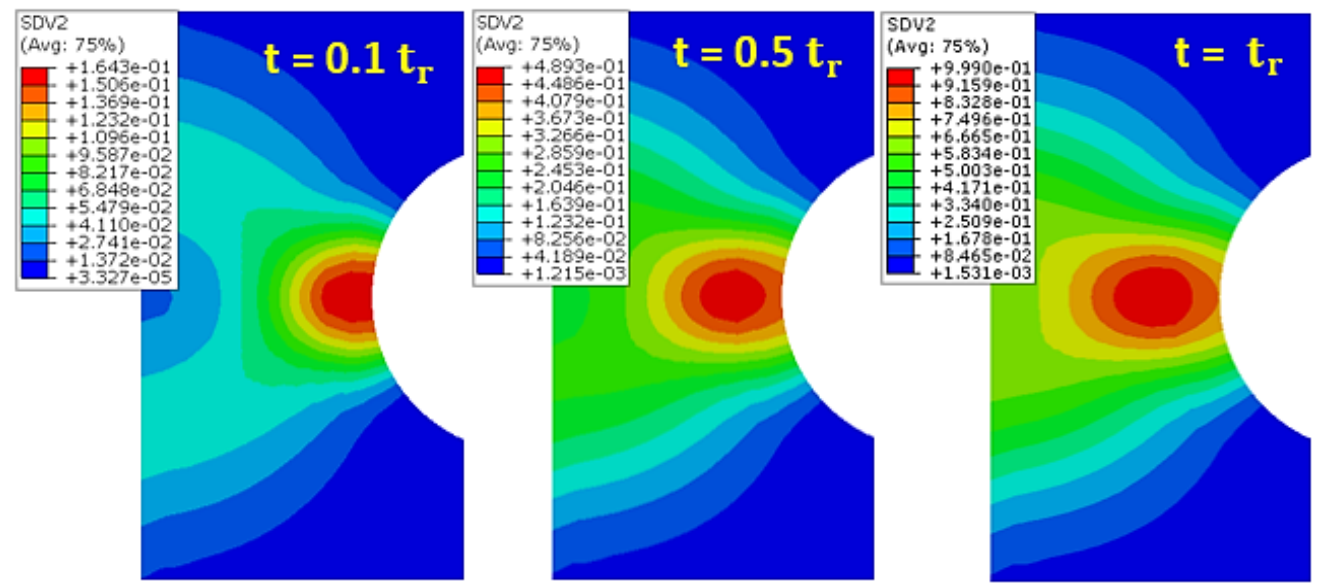

(c) 


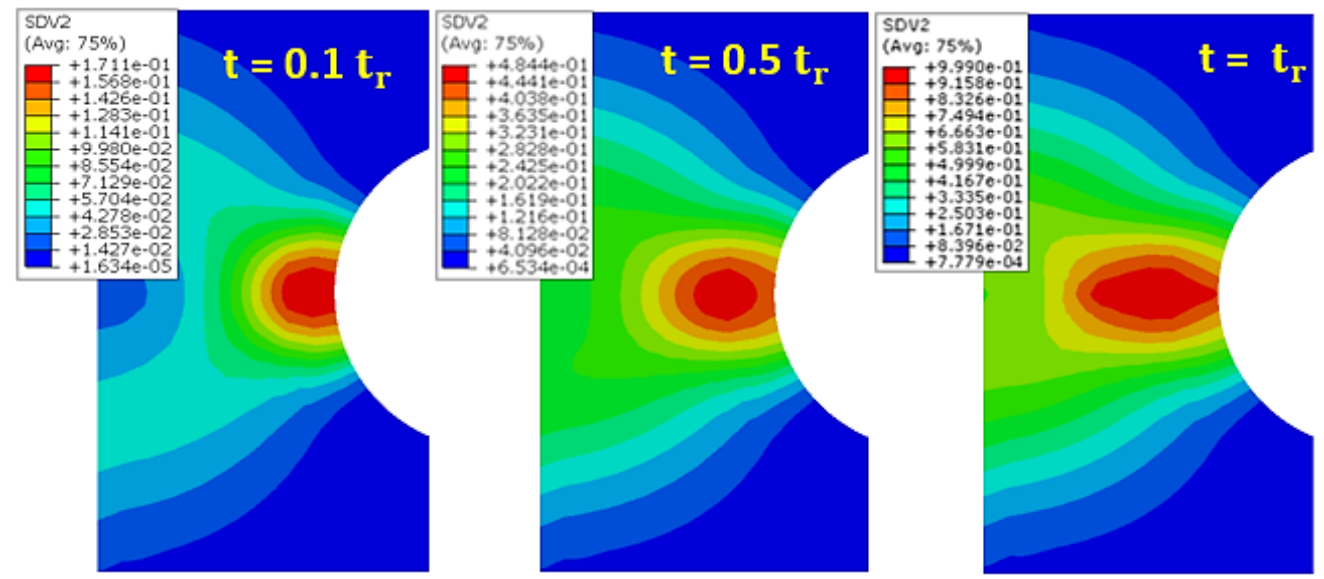

(d)

Figure 11. Creep damage distribution around the notch region at different creep time for acuity $=3.0$, (a) net stress $=$ $187 \mathrm{MPa}$, (b) net stress $=202 \mathrm{MPa}$, (c) net stress $=222 \mathrm{MPa}$, and (d) net stress $=244 \mathrm{MPa}$.

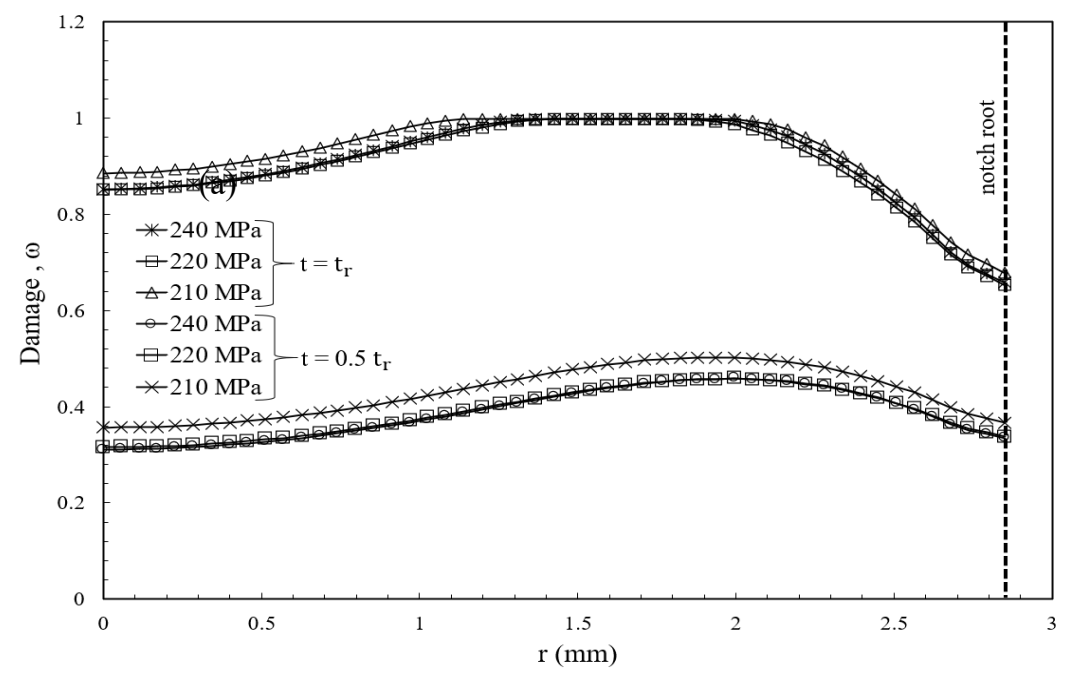

(a) acuity $=2.28$

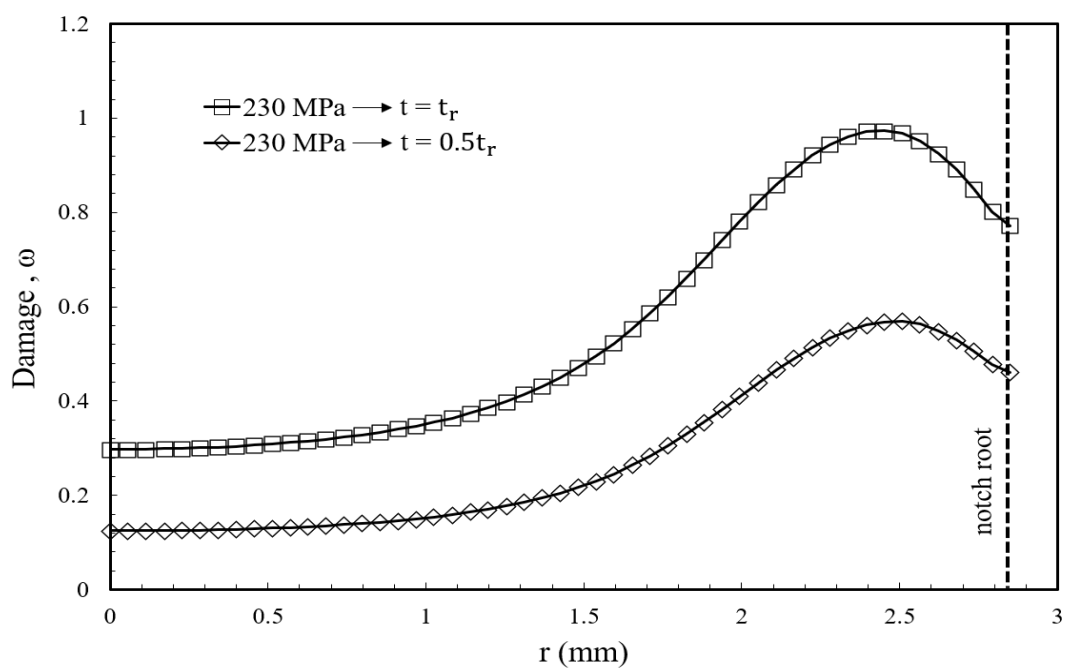

(b) acuity $=4.56$ 


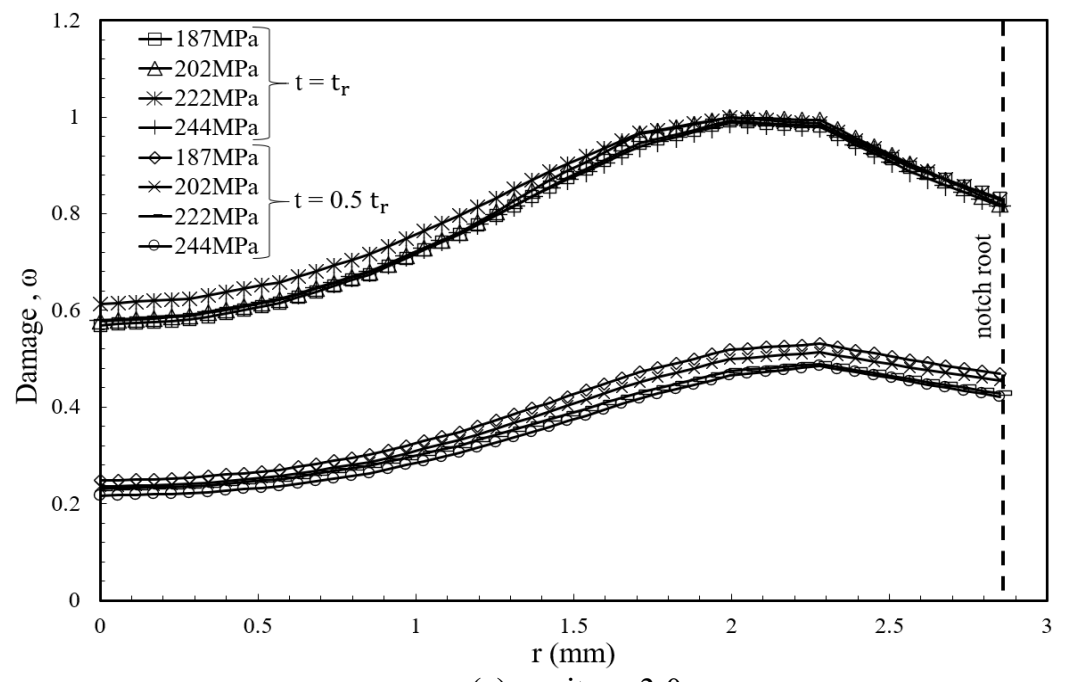

(c) acuity $=3.0$

Figure 122. Creep damage distribution along the notch plane at $t=0.5 t_{r}$ and $t=t_{r}$.

The triaxiality and equivalent creep strain along the notch throat are examined to understand better the rupture behaviour and damage development in the notched bar having different notch acuities. It is well known that the reduction of ductility depends on the triaxiality factor. The distribution of triaxiality factor and equivalent creep strain along the notch throat plane at $\mathrm{t}=0.5 \mathrm{tr}$ is presented from Figure 13 (a) to $13(\mathrm{c})$. The triaxiality factor is proven to have a substantial relationship with notch acuity. In the case of the specimen having higher acuity, the triaxiality has a peak value near the notch root and gradually decreases as it approaches the notch centre. On the other hand, the lower value of acuity shows a different trend compared to the higher value of acuity. The maximum value of triaxiality was found to be at the notch centre and the lower value at the notch root for all applied stresses for lower acuity. It is also well established that [7], high triaxiality causes brittle fracture while low triaxiality is responsible for ductile fracture. As a result, brittle-like fractures are frequently detected on higher-acuity creep samples. Also, considering equivalent creep strain, it can be observed that for specimens having a higher value of acuity, the equivalent creep strain is very low except at the root, and the behaviour remains unchanged over the creep time. Comparing to the lower value of acuity, the creep strain at the centre is slightly higher, and the value tends to be uniform (along the notch throat) as the acuity approaching $\sim 0$ (smooth bar).

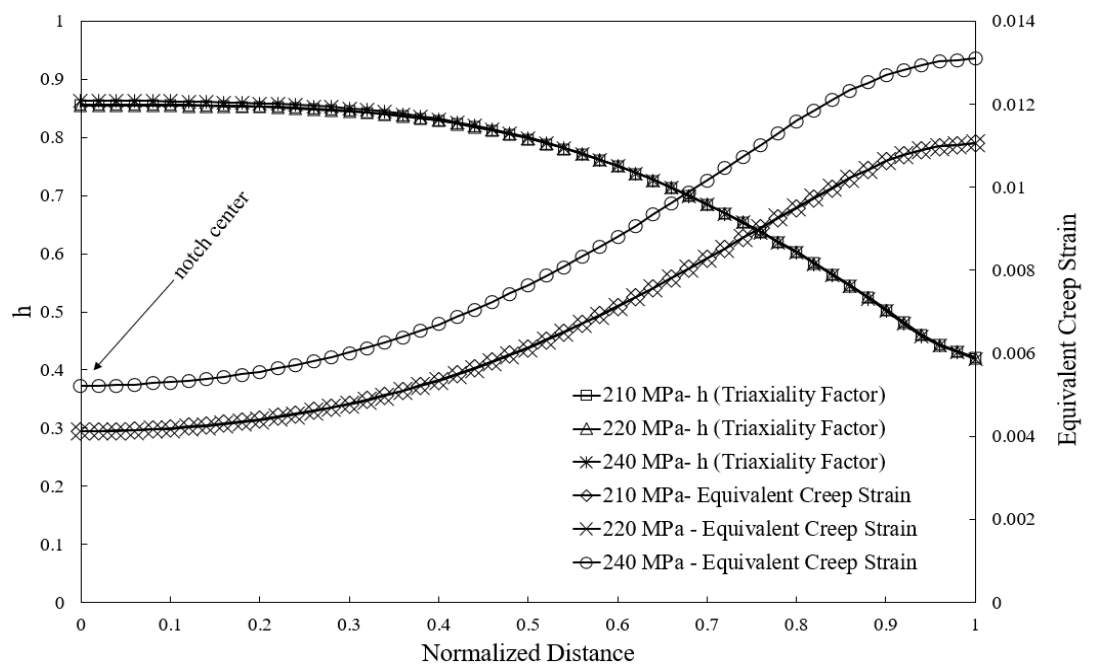

(a) acuity $=2.28$ 


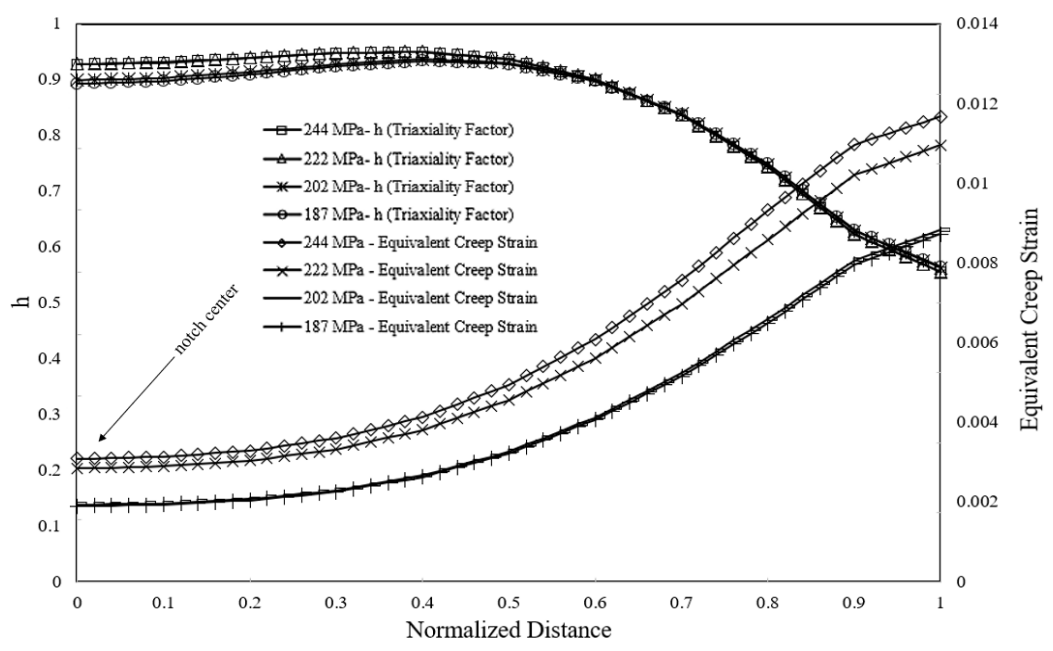

(b) acuity $=3.0$

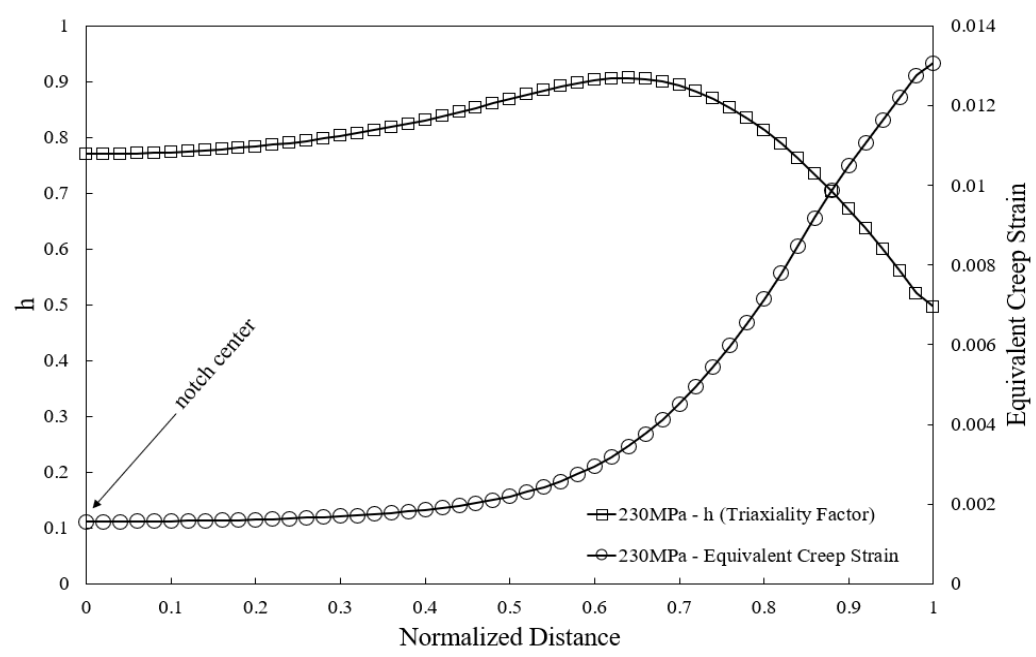

(c) acuity $=4.56$

Figure 13. Triaxiality Factor and equivalent creep strain distribution for the notched bar at $t=0.5 t_{r}$ of different acuity.

\section{CONCLUSION}

In the present paper, prediction on creep rupture life of Grade 91 notched bar sample of ex-service and as-received material conditions has been performed. A different creep coefficient, A (considering mean and upper/lower data bounds), has been employed in the numerical modelling to tailor both conditions. It is found that all experimental creep rupture data falls between the upper/lower bound of the prediction curve. A good prediction is obtained for ex-service material when employing the mean best fit data of minimum creep strain rate while for as-received material, lower bounds creep coefficient should be used. It implies that at the same stress level, ex-service material deforms at a faster rate compared to the as-received.

As the acuity increases, the damage concentrates on a very small area in the notch area, and others remain at a low damage state. This is responsible for the life improvement of higher acuity specimens. It is also found that for all considered geometries, damage initiates at the location offset from the notch root, which may be influenced by the stress triaxiality and equivalent creep strain value. Note that only three notch acuities ratios have been investigated in the present study. When the experimental data becomes available, a range of notch acuity ratios should be simulated, including different temperature ranges to validate the employed model further.

\section{ACKNOWLEDGEMENT}

The authors would like to express gratitude to the Ministry of Higher Education (MOHE) Malaysia for funding this research under the Fundamental Research Grant Scheme FRGS/1/2019/TK03/UMP/02/2 (university reference RDU1901107) and Universiti Malaysia Pahang for additional financial support under the Internal Grant RDU1803135.

\section{REFERENCES}

[1] A. Nitsche, D. Allen, and P. Mayr, "Damage assessment of creep affected weldments of a Grade 91 header component after long-term high temperature service," Weld. World, vol. 59, no. 5, pp. 675-682, 2015, doi: 10.1007/s40194-015-0243-2. 
[2] Y. Chang, et al., "Research on representative stress and fracture ductility of P92 steel under multiaxial creep," Eng. Fail. Anal., vol. 59, pp. 140-150, 2016, doi: 10.1016/j.engfailanal.2015.09.011.

[3] X. Xu, G. Z. Wang, F. Z. Xuan, and S. T. Tu, "Effects of creep ductility and notch constraint on creep fracture behavior in notched bar specimens," Mater. High Temp., vol. 33, no. 2, pp. 198-207, 2016, doi: 10.1080/09603409.2016.1144498.

[4] Y. Chang, et al., "The effect of multiaxial stress state on creep behavior and fracture mechanism of P92 steel," Mater. Sci. Eng. A, vol. 636, pp. 70-76, 2015, doi: 10.1016/j.msea.2015.03.056.

[5] N. A. Alang and N. A. Razak, "Application of ductility exhaustion based damage model to predict creep rupture time of grade 92 steel," IOP Conf. Ser. Mater. Sci. Eng., vol. 670, no. 1, 2019, doi: 10.1088/1757-899X/670/1/012001.

[6] S. Goyal and K. Laha, "Creep life prediction of 9Cr-1Mo steel under multiaxial state of stress," Mater. Sci. Eng. A, vol. 615, pp. 348-360, 2014, doi: 10.1016/j.msea.2014.07.096.

[7] L. Zhao, N. Alang, and K. Nikbin, "Investigating creep rupture and damage behaviour in notched P92 steel specimen using a microscale modelling approach," Fatigue Fract. Eng. Mater. Struct., vol. 41, no. 2, pp. 456-472, 2018, doi: $10.1111 /$ ffe. 12713 .

[8] A. Benaarbia, et al., "Investigation of short-term creep deformation mechanisms in MarBN steel at elevated temperatures," Mater. Sci. Eng. A, vol. 734, pp. 491-505, 2018, doi: 10.1016/j.msea.2018.06.063.

[9] L. Cipolla et al., "Microstructural Evolution During Long Term Creep Tests of 9\%Cr Steel Grades," in Volume 9: Eighth International Conference on Creep and Fatigue at Elevated Temperatures, Jan. 2007, pp. 445-459. doi: 10.1115/CREEP200726030.

[10] J. W. Zhang, G. Z. Wang, F. Z. Xuan, and S. T. Tu, "The influence of stress-regime dependent creep model and ductility in the prediction of creep crack growth rate in Cr-Mo-V steel," Mater. Des., vol. 65. pp. 644-651, 2015, doi: 10.1016/j.matdes.2014.09.070.

[11] T. Tu, et al., "Effect of stress regime-dependent creep behaviour on measurement of creep strain rate based on small specimen techniques," Fatigue Fract. Eng. Mater. Struct., vol. 42, no. 1. pp. 187-196, 2019, doi: 10.1111/ffe.12894.

[12] N. A. Alang and K. Nikbin, "An analytical and numerical approach to multiscale ductility constraint based model to predict uniaxial/multiaxial creep rupture and cracking rates," Int. J. Mech. Sci, vol. 135. pp. 342-352, 2018, doi: 10.1016/j.ijmecsci.2017.11.030.

[13] A. C. F. Cocks and M. F. Ashby, “On creep fracture by void growth,” Prog. Mater. Sci., vol. 27, no. 3-4, pp. 189-244, 1982, doi: 10.1016/0079-6425(82)90001-9.

[14] J. R. Rice and D. M. Tracey, "On the ductile enlargement of voids in triaxial stress fields," J. Mech. Phys. Solids, vol. 17, no. 3, pp. 201-217, 1969, doi: 10.1016/0022-5096(69)90033-7.

[15] M. W. Spindler, "The multiaxial creep ductility of austenitic stainless steels," Fatigue Fract. Eng. Mater. Struct., vol. 27, no. 4, pp. 273-281, 2004, doi: 10.1111/j.1460-2695.2004.00732.x.

[16] H. Li and D. Mitchell, "Microstructural characterisation of P91 steel in the virgin, service exposed and post-service renormalised conditions," Steel Res. Int., vol. 84, no. 12. pp. 1302-1308, 2013, doi: 10.1002/srin.201300055.

[17] N. A. Razak, "Creep and creep-fatigue interaction in new and service exposed P91 steel," PhD thesis, Imperial College London, UK, 2018.

[18] ASTM E292-18, "Standard test methods for conducting time-for-rupture notch tension tests of materials," ASTM International.

[19] N. A. Alang and K. Nikbin, "A new approach to predict creep rupture of Grade 92 steel under multiaxial stress states," Int. J. Mech. Sci., vol. 163, no. June, 2019, doi: 10.1016/j.ijmecsci.2019.105096.

[20] Sawada K, Kimura K, Abe F et al. Data sheets on the elevated-temperature properties of 9Cr-1Mo-V-Nb steel tubes for boilers and heat exchangers (ASME SA-213/SA-213M Grade T91), 9Cr-1Mo-V-Nb steel plates for boilers and pressure vessels (ASME SA-387/SA-387M Grade 91) and 9Cr-1Mo-V-Nb steel seamless pipe for high temperature service (ASME SA-335/SA-335M Grade P91). NIMS creep data sheet No. 43A: National Institute for Materials Science; 2014. doi: 10.11503/nims.1047.

[21] B. K. Choudhary and J. Christopher, "Influence of temperature and strain rate on tensile deformation and fracture behaviour of boron added P91 steel," Int. J. Press. Vessel. Pip., vol. 171, no. April 2016, pp. 153-161, 2019, doi: 10.1016/j.ijpvp.2019.02.014.

[22] J. J. Han et al., "Prediction of creep crack initiation and growth for P91 at $600^{\circ} \mathrm{C}$ using MOD-NSW model," Strength, Fract. Complex., vol. 9, no. 1, pp. 125-136, 2015, doi: 10.3233/SFC-150184.

[23] V. Sklenicka, K. Kucharová, P. Král, M. Kvapilová, and J. Dvorák, “Applicability of empirical formulas and fractography for assessment of creep life and creep fracture modes of tempered martensitic 9\% rr steel," Kovove Materialy, vol. 55, no. 2. pp. 69-80, 2017, doi: 10.4149/km-2017-2-69.

[24] M. van Rooyen, T. H. Becker, J. E. Westraadt, and G. Marx, "Measurement of creep deformation of ex-service $12 \%$ Cr steel using digital image correlation," J. Strain Anal. Eng. Des., vol. 55, no. 3-4, pp. 71-85, 2020, doi: $10.1177 / 0309324720904517$.

[25] K. C. Sahoo, V. D. Vijayanand, S. Goyal, P. Parameswaran, and K. Laha, "Influence of temperature on multiaxial creep behaviour of 304HCu austenitic stainless steel," Mater. Sci. Technol. (United Kingdom), vol. 35, no. 18, pp. 2181-2199, 2019, doi: 10.1080/02670836.2019.1664707. 